\title{
Factors Associated with Inequalities in Access to Health Care to Mbujimayi (Kasai Oriental/DR Congo)
}

\author{
Kabongo Mwamba A. Guillaume ${ }^{1}$, Bukasa Tshilonda J. Christophe1, \\ Kankologo Biakulamabo Christine ${ }^{1}$, Mbuyi Kabeya J. Henock ${ }^{1}$, Mbuyi Mishinda Anaclet ${ }^{1}$, \\ Kabambi Bukasa Valentin', Mishika Lukusa Patricia², Mutombo Kabamba André3, \\ Wembonyama Okitotshio Stanis ${ }^{2,4}$
}

\author{
${ }^{1}$ Higher Institute of Medical Techniques Mbujimayi, Mbujimayi, DR Congo \\ ${ }^{2}$ Department of Health Public, University of Lubumbashi, Lubumbashi, DR Congo \\ ${ }^{3}$ Department of Pediatric, University of Official Mbujimayi, Mbujimayi, DR Congo \\ ${ }^{4}$ Department of Pediatric, University of Lubumbashi, Lubumbashi, DR Congo \\ Email: *guillaumemwamba25863@gmail.com
}

How to cite this paper: Guillaume, K.M.A., Christophe, B.T.J., Christine, K.B., Henock, M.K.J., Anaclet, M.M., Valentin, K.B., Patricia, M.L., André, M.K. and Stanis, W.O. (2019) Factors Associated with Inequalities in Access to Health Care to Mbujimayi (Kasai Oriental/DR Congo). Open Access Library Journal, 6: e5666.

https://doi.org/10.4236/oalib.1105666

Received: August 6, 2019

Accepted: October 11, 2019

Published: October 14, 2019

Copyright $\odot 2019$ by author(s) and Open Access Library Inc.

This work is licensed under the Creative Commons Attribution International License (CC BY 4.0).

http://creativecommons.org/licenses/by/4.0/

\begin{abstract}
Objective: Mbujimayi like the other African cities where the environmental, social and economic problems, promote the development of urban pathology, several factors limit or promote access to quality health care services especially for slum dwellers. The objective of this study was to analyze factors associated with seeking care in this city. Material and Methods: This study was conducted in 2010 on the therapeutic use in six health zones of the 10 areas that make up the urban medical district of the city with a cross-sectional survey of 386 households. To study the association of different factors, we relied on crosstabs and statistical associations: we connected, one by one, the independent variables to those characterizing the use of care; we evaluated the significance of the statistical relationships subjecting the consequences we assume they induced the chi-square test. The degree of significance of the associations has been indicated by the value of $p<0.05$. Data processing was carried out using the software Epi-Info 6 version 3.5. 1, 2008, and Excel for tables. Results: The results show that therapeutic routes are as diverse as health care supply is varied. It appears from this study that $94.8 \%$ of households had at least one case of disease, $70.5 \%$ used modern health care, $17.1 \%$ consulted traditional healers, $4.3 \%$ practiced self-medication and $8.1 \%$ gave up to care. $70.3 \%$ have resorted to private structures, $85.7 \%$ used private structures. The corresponding description said the gender of the household head, sex and age of the patient, the level of education of the household head, the distance, the supposed cause of the disease and care of financing are fac-
\end{abstract}


tors associated with access to both modern and traditional treatments $(\mathrm{p}<$ $0.05)$.

\section{Subject Areas}

Health Policy, Public Health

\section{Keywords}

Inequality, Access, Care

\section{Introduction}

The Universal Declaration of Human Rights (1948) argued for everyone "the right to a standard of living adequate for the health and well-being of himself and his family." The right to health is thus one of the fundamental human rights.

However, there is still around the world, the existence of major disparities in access to care. This problem largely depends on the type of health system, its organization, its funding and the fact that it favors or not the social protection systems regardless of their financing. In Africa, analyzes of health reforms of recent decades all lead to the same conclusion: The fair aspect of public health policy has been neglected and the first concerns of the players focused on the generalization of care across a wide coverage Geographical [1] [2] [3].

Indeed, the different policies (Primary Health Care, Alma-Ata in 1978; cost recovery; Bamako Initiative in 1987) have generalized the pricing of medical procedures and the sale of drugs, from basic care to the care hospital. These policies on the one hand, strengthened the quality of care available, but on the other hand, made them easily accessible at a fraction of the population [4] [5]. The fundamental goal of health for all can only be achieved in these conditions.

Inequalities in access to care are alarming: according to the global report of the United Nations Development Program (UNDP), 2.5 billion people lack access to basic health facilities [6].

A study on the capitals of five countries in West Africa (Ivory Coast, Guinea, Mali, Niger and Senegal), found that $52 \%$ of patients reported using modern health care in primary care. The poor were significantly less use of modern care than wealthier people (54\% vs. $67.7 \%$ ) [7].

Another cross-sectional survey conducted a few years later in Burkina Faso from 1604 households (12,775 people), revealed significant different inequalities in access to care. More than half of sick people from households income quintile highest used public services by the end of first week of illness episode, while less than one in four did among households the poorest. Two weeks after the onset of the disease, one in two men visited a public health facility for care while in the case of less than one in two women [8]. In all these studies, the authors focused on more financial capacity as if it would be the only barrier to access to care. 
The unequal access to care is highly dependent on where you are. In some countries, particularly in developing countries, barriers accumulate for people who need access to health care: difficulties in finding certain drugs stock outs, lack of sanitation or treatment, lack of qualified medical personnel and information exchanges, or the long distances to reach a health center often compounded by an environment of insecurity and we add the lack of money and the high cost of care.

Beyond the influence of age, gender and health status, socioeconomic characteristics and the benefit of a supplementary health insurance affect health care consumption. While the structure of consumption of people from socially advantaged rather turned towards outpatient care, the more modest, tends to focus on care to the hospital. Medical consumption increases with the cultural capital. Cultural factors are partly responsible for differences in health behavior of individuals to the extent that they reflect very different lifestyles [9] [10] [11]. To these factors may add the expected competence of the care provider [12].

Despite commitments and various health reforms that have succeeded in DR Congo, the population's health status is far from brilliant, whatever the health indicator used and the weak results on efficiency benefits show that many problems still exist [13]. Added to this are the prevalence of epidemic and endemic diseases (malaria, cerebro-spinal meningitis, measles, ARI, diarrhea, whooping cough), HIV/AIDS, tuberculosis... which are the basis of the excessive load morbidity and mortality.

While these health problems exacerbated by the multifaceted crises cause strong because demand for care including poor living conditions, personal and public hygiene, malnutrition, etc., the health infrastructure of the city Mbujimayi like the other cities in Africa, are increasingly unable to meet this demand due to dilapidated infrastructure, lack of equipment and medicines, to demotivation of staff, etc. Most of these health facilities are private. The existence of this offers varied care and can lead to a multitude of possible therapeutic remedies often cause a poor use of health services. This diversity of supply of care, adds an even greater diversity of care of an omnipresent traditional medicine. Thus, one bad match various therapeutic offers, between which the patient must choose at least adopt them all. A key aspect of environmental health problems is the simultaneous and frequent recourse to both care system, the modern and traditional therapy system that are sometimes complementary [14].

The objective of this study is to analyze the factors that are associated with inequalities in access to health care Mbujimayi.

\section{Method}

The study population included 369 households in the city of Mbujimayi.

As part of our study have made use of probability sampling, precisely the proportionate stratified random probability sampling. The ten health zones that make up the Mbujimayi Sanitary District have formed strata and health areas of 
sub-strata. This is a cross quantitative study used a correlational design specifications to describe inequalities in access to care and associated factors

Were in our sample households capita health areas selected for roughly three months before the passage of the investigators and who agreed to participate in the survey.

In order to mitigate the risk of non responses that could occur in such studies, and not to fall below the minimum size that ensures accuracy in estimating the parameters, we added $5 \%$ or 20 units of sample as "Not responding" what brought our sample to 400 households. These households were distributed proportionally to the population size of each of six selected health zones.

In this study, the raw data collected and recorded on the instrument were compiled and entered.

The calculations of percentages, proportions and means were conducted among groups.

To study the association of different factors, we relied on crosstabs and statistical associations: we connected, one by one, the independent variables to those characterizing the use of care; we evaluated the significance of the statistical relationships subjecting the consequences we assume they induced the chi-square test. The degree of significance of the associations indicated by the value of $\mathrm{p}$.

Data processing was carried out using the software Epi-Info Version 3.5. 1, 2008, and Excel for tables.

\section{Ethical Considerations}

This study had been approved by the Interuniversity Ethics Committee of the city of Mbuji-Mayi. Then free and informed consent was obtained in writing for any caesarized woman who participated in the study.

\section{Results}

\subsection{Respondents Socio-Demographic and Economic Characteristics}

The results recorded in the Table 1 , show that $57.3 \%$ of household heads were male, the mean age was $40 \pm 14$ years, $60 \%$ of household heads were working in private practice, $29.8 \%, 90.8 \%$ were at least at the school, the average monthly household income was $124 \pm 108 \$$ (minimum $\$ 30$ and maximum $\$ 900$ ). The average size of households was $6.6 \pm 3.2$ persons (Minimum 1 and maximum 22), $55.6 \%$ of households lived within $5 \mathrm{~km}$ from the healthcare facility.

\subsection{Diseases State in Households and Characteristics of the Patient}

In Table 2, 94.8\% of the households had at least one case of disease during the last month before the survey. $58.3 \%$ of ill persons were male, $40.7 \%$ of patients were aged 0 to 5 years, $84 \%$ of cases of disease were linked to biomedical causes and $62 \%$ were considered not serious, $71.3 \%$ of heads of households bear themselves the costs of care. 


\subsection{Behavior of the Population to Morbid Phenomena}

In Figure 1, we see that $70.5 \%$ of households had at least one case of disease have resorted to the hospital or health center. While $17.1 \%$ used traditional medicine, $8.1 \%$ remained without care and $4.3 \%$ practiced self-medication (Traditional and modern).

Table 1. Distribution of respondents according to socio-demographic and economic characteristics.

\begin{tabular}{|c|c|c|}
\hline Variable & Effective $(\mathrm{n}=400)$ & $\%$ \\
\hline \multicolumn{3}{|l|}{ Sex } \\
\hline Male & 215 & 58.3 \\
\hline Female & 154 & 41.7 \\
\hline \multicolumn{3}{|l|}{ Age } \\
\hline$<30$ & 127 & 34.4 \\
\hline $30-50$ & 166 & 45 \\
\hline$>50$ & 76 & 20.6 \\
\hline \multicolumn{3}{|l|}{ Profession } \\
\hline salaried & 116 & 29.8 \\
\hline liberal & 237 & 60.9 \\
\hline No occupation & 36 & 9.3 \\
\hline \multicolumn{3}{|l|}{$\mathrm{CM}$ instruction } \\
\hline illiterate & 34 & 9.2 \\
\hline Primary & 186 & 50.4 \\
\hline Sec \& university & 149 & 40.4 \\
\hline \multicolumn{3}{|l|}{ Religion } \\
\hline not Christian & 78 & 20.1 \\
\hline Christians & 311 & 79.9 \\
\hline \multicolumn{3}{|l|}{ Returned (\$) } \\
\hline$<100$ & 235 & 63.7 \\
\hline$\$ 100-150$ & 57 & 15.4 \\
\hline$>150$ & 77 & 20.9 \\
\hline \multicolumn{3}{|l|}{ household size } \\
\hline$<6$ & 212 & 57.5 \\
\hline $6-10$ & 120 & 32.5 \\
\hline$>10$ & 37 & 10 \\
\hline \multicolumn{3}{|l|}{ Distance } \\
\hline$<5 \mathrm{~km}$ & 205 & 55.6 \\
\hline$>5 \mathrm{~km}$ & 184 & 44.4 \\
\hline
\end{tabular}


Table 2. Distribution of respondents according to disease state in households and characteristics of the patient.

\begin{tabular}{|c|c|c|}
\hline Variable & Effective & $\%$ \\
\hline \multicolumn{3}{|c|}{ 1) Disease cases in households ( $\mathrm{N}=389)$} \\
\hline No & 20 & 5.2 \\
\hline Yes & 369 & 94.8 \\
\hline \multicolumn{3}{|c|}{ 2) Characteristics of the patient } \\
\hline \multicolumn{3}{|l|}{ Sex of the patient } \\
\hline Male & 215 & 58.3 \\
\hline Female & 154 & 41.7 \\
\hline \multicolumn{3}{|l|}{ Age of the patient } \\
\hline $0-5$ & 150 & 40.7 \\
\hline $6-18$ & 92 & 24.9 \\
\hline$>18$ & 127 & 34.4 \\
\hline \multicolumn{3}{|l|}{ Etiological beliefs (369) } \\
\hline Biomedical & 310 & 84.0 \\
\hline Supernatural/Metaphysics & 59 & 160 \\
\hline \multicolumn{3}{|c|}{ Perception of the state of the disease $(=369)$} \\
\hline No serious & 232 & 62.9 \\
\hline Serious & 137 & 37.1 \\
\hline \multicolumn{3}{|l|}{ care financing options } \\
\hline oneself & 263 & 71.3 \\
\hline Employer & 70 & 19 \\
\hline Other (Church kinship ...) & 9.7 & 9.7 \\
\hline
\end{tabular}

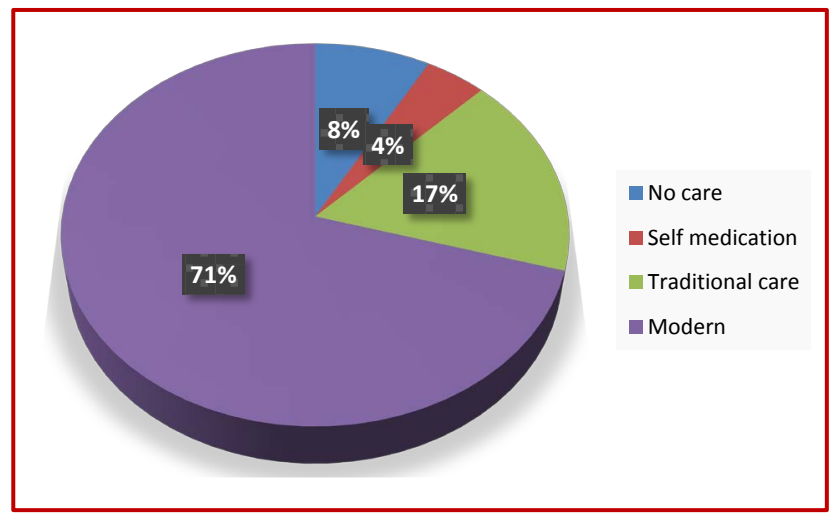

Figure 1. Distribution of respondents according to the behavior in households for illness.

Figure 2 shows that $71 \%$ of households have resorded to private structures cas against $29.4 \%$ who were in the state structures.

From observation of Figure 3, we can say that among the 260 households with at least one member used a modern health service in case of a health problem in the last three months of the survey, $70.3 \%$ have resorted to private structures against $29.6 \%$ for state structures. The reasons given for the choice of private 
structures are lack of better (85.7\% vs. $14.3 \%)$; good quality health care $(74.8 \%$ vs. $25.2 \%$ ), cost of care (61.3\% vs $38.7 \%$ ) and subscription (55.9\% vs $44.1 \%$ ).

The results in Figure 4 indicate that $80.7 \%$ of those who had not used the modern care cited lack of money as a result, $12.8 \%$ because of distance, lack of transportation, $4.6 \%$ were prevented by religious prohibitions, customary and $1.8 \%$ for reasons mistrust vis-à-vis modern care.

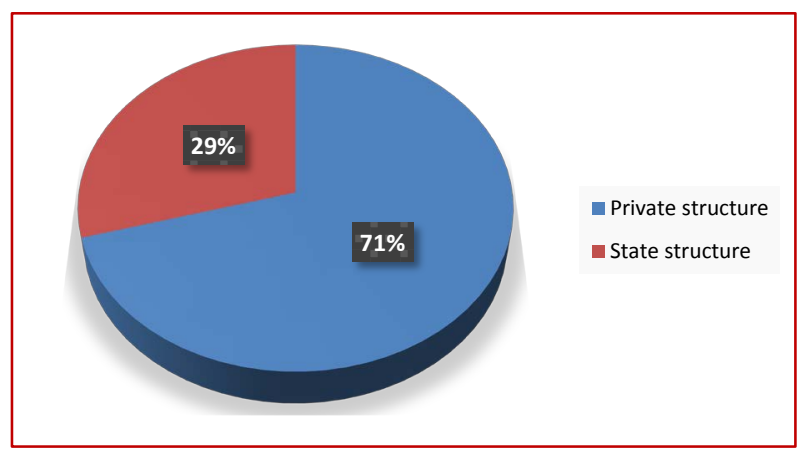

Figure 2. Distribution of respondents according to the status of the care structure.

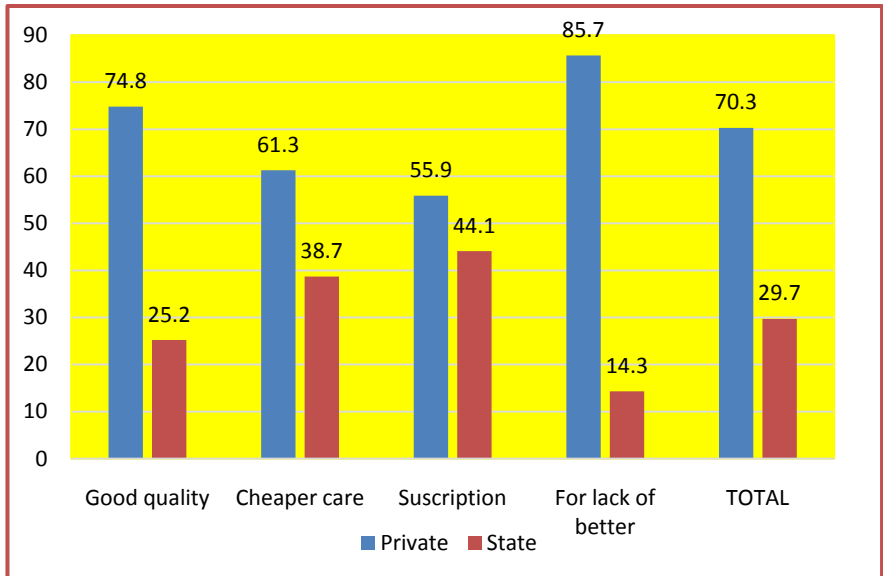

Figure 3. Distribution of respondents as reasons for choosing modern health facility.

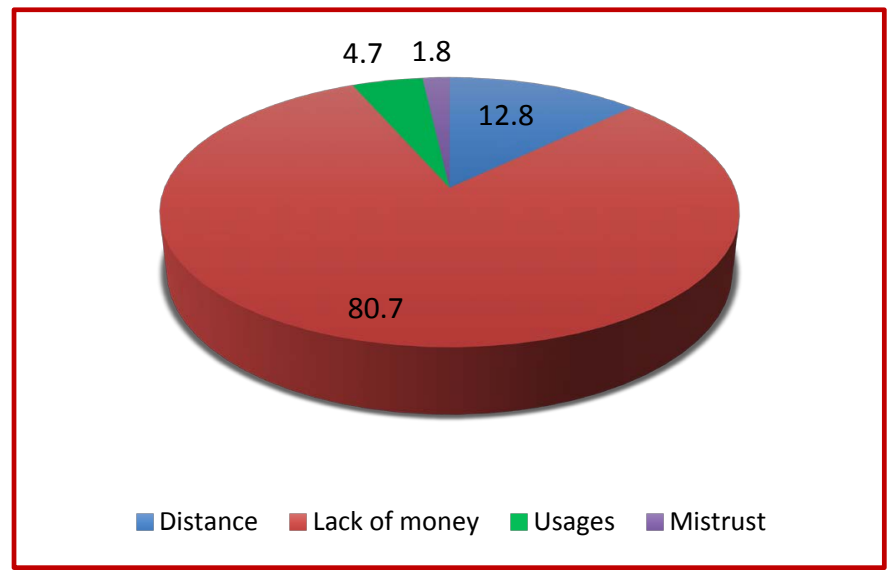

Figure 4. Distribution of respondents according to the reasons for non-use of modern care. 


\subsection{Results of Bi-Varied Analysis}

Analysis of the results of the Table 3 reveals a significant difference for the age of the household head, the patient's age and occupation of the household head. The difference is very significant for the sex of the patient, the head of household, distance and etiological belief care financing terms $(\mathrm{p}<0.05)$.

Table 3. Factors associated with health seeking.

\begin{tabular}{|c|c|c|c|c|c|c|c|c|c|}
\hline \multirow[t]{2}{*}{ Variable } & \multicolumn{2}{|c|}{$\begin{array}{c}\text { Care } \\
\text { modern }\end{array}$} & \multicolumn{2}{|c|}{$\begin{array}{c}\text { Care } \\
\text { traditional }\end{array}$} & \multicolumn{2}{|c|}{ Self-medication } & \multicolumn{2}{|c|}{ No recourse } & \multirow[t]{2}{*}{$\mathrm{P}$} \\
\hline & Effective & $\%$ & Effective & $\%$ & Effective & $\%$ & Effective & $\%$ & \\
\hline $\begin{array}{l}\text { Gender of the } \\
\text { household head }\end{array}$ & & & & & & & & & 0.408 \\
\hline Male & 214 & 70 & 44 & 15.1 & 14 & 4.8 & 20 & 6.8 & \\
\hline Female & 46 & 59.7 & 19 & 24.7 & 2 & 2.6 & 10 & 3.4 & \\
\hline $\begin{array}{c}\text { Age of household } \\
\text { head }\end{array}$ & & & & & & & & & $0.022^{*}$ \\
\hline$<30$ & 80 & 63 & 23 & 18.9 & 5 & 3.9 & 19 & 15 & \\
\hline$>30$ & 180 & 74.4 & 40 & 16.5 & 11 & 4.5 & 11 & 4.5 & \\
\hline Sex of the patient & & & & & & & & & $0.000^{* *}$ \\
\hline Male & 128 & 59.5 & 51 & 23.7 & 12 & 5.6 & 24 & 11.2 & \\
\hline Female & 132 & 85.7 & 12 & 7.8 & 4 & 2.6 & 6 & 3.9 & \\
\hline Age of the patient & & & & & & & & & $0.030^{*}$ \\
\hline $0-5$ & 115 & 76.7 & 21 & 14 & 4 & 2.7 & 10 & 6.7 & \\
\hline$>5$ & 145 & 66.2 & 42 & 19.2 & 12 & 5.5 & 20 & 9.1 & \\
\hline Profession & & & & & & & & & $0.0156^{*}$ \\
\hline Employee/Liberal & 236 & 70.9 & 60 & 18 & 13 & 3.9 & 24 & 7.2 & \\
\hline No occupation & 24 & 66.7 & 3 & 8.3 & 3 & 8.3 & 6 & 16.7 & \\
\hline Instruction & & & & & & & & & $0.000^{* *}$ \\
\hline Illiterate/Primary & 146 & 66.4 & 42 & 19.1 & 10 & 4.5 & 22 & 10 & \\
\hline Sec \& Higher & 114 & 76.5 & 21 & 14.1 & 6 & 4 & 8 & 5.4 & \\
\hline Religion & & & & & & & & & 0.408 \\
\hline not Christian & 52 & 66.7 & 17 & 21.8 & 4 & 5.1 & 5 & 6.4 & \\
\hline Christians & 208 & 71.5 & 46 & 15.8 & 12 & 4.1 & 25 & 8.6 & \\
\hline Household & & & & & & & & & 0.374 \\
\hline$<100$ & 159 & 67.7 & 43 & 18.3 & 9 & 4.2 & 20 & 9.4 & \\
\hline$>100$ & 101 & 73.2 & 20 & 14.5 & 7 & 5.1 & 10 & 7.2 & \\
\hline household size & & & & & & & & & 0.435 \\
\hline$<6$ & 146 & 68.9 & 37 & 17.5 & 9 & 4.2 & 20 & 9.4 & \\
\hline$>6$ & 114 & 72.6 & 26 & 16.6 & 7 & 4.6 & 10 & 6.4 & \\
\hline
\end{tabular}


Continued

\begin{tabular}{|c|c|c|c|c|c|c|c|c|c|}
\hline Distance & & & & & & & & & $0.000^{* *}$ \\
\hline$\leq 5 \mathrm{~km}$ & 172 & 83.9 & 16 & 7.8 & 7 & 3.4 & 10 & 4.9 & \\
\hline$>5 \mathrm{~km}$ & 88 & 53.7 & 47 & 28.7 & 9 & 5.5 & 20 & 12.2 & \\
\hline $\begin{array}{l}\text { supposed cause of } \\
\text { the disease }\end{array}$ & & & & & & & & & $0.000^{* *}$ \\
\hline Biomedical & 230 & 74 & 47 & 15.3 & 12 & 3.9 & 19 & 6.2 & \\
\hline $\begin{array}{c}\text { Supernatural/ } \\
\text { Metaphysics }\end{array}$ & 30 & 51.7 & 16 & 26.2 & 4 & 6.6 & 11 & 18 & \\
\hline $\begin{array}{c}\text { State assumed the } \\
\text { disease }\end{array}$ & & & & & & & 0.145 & & $0.000^{* *}$ \\
\hline Serious & 17 & 58.6 & 4 & 13.8 & 4 & 13.8 & 4 & 13.8 & \\
\hline No serious & 243 & 70.6 & 26 & 7.6 & 59 & 17.4 & 12 & 3.5 & \\
\hline $\begin{array}{l}\text { Care Financing } \\
\text { System }\end{array}$ & & & & & & & & & $0.000^{\star *}$ \\
\hline Direct & 209 & 79.5 & 29 & 11 & 9 & 3.4 & 16 & 9.8 & \\
\hline Other & 51 & 50 & 34 & 33.3 & 7 & 6.9 & 10 & 9.8 & \\
\hline
\end{tabular}

${ }^{*}$ Significant difference; ${ }^{* *}$ very significant difference.

\section{Discussion}

The major differences of use of services of care observed in the population of the city of Mbujimayi reveal the state of health care delivery that determines somewhat different therapeutic routes based spaces and social categories. This study's general objective determining factors associated with inequalities in access to health care. The analyzes are based on data from a survey conducted among 389 households in the city of Mbujimayi which 369 households experienced at least one case of disease three months before our investigation.

\subsection{Respondents Socio-Demographic and Economic Characteristics}

Regarding the gender of household head, we found that $80.2 \%$ of households were headed by men. Not far different from the social situation of the province, these observations are slightly higher than those presented nationally in DCSRP [13], which are the proportions of households headed by men and women respectively and $86.2 \% 13.8 \%$. This profile is characteristic of the social organization of the people in our environment where traditionally dominated patriarchy. The average head of household age was $40 \pm 14$ years. $60.9 \%$ of household heads were working in private practice. This situation is the result of self-employment phenomenon observed in Kasaï Oriental, where $65 \%$ of employees working for their own account [13]. The average size of households was $6.6 \pm 32$ persons. This average is slightly above that presented in Kasai Oriental and the DRC in 2006 [6]. While it remains lower than that found in Kadutu (South Kivu/DRC) or $7.6 \%$ [15]. $55.6 \%$ of households live within $5 \mathrm{~km}$ of a health facility. Different 
situation from that of the interior of the province, where $65.6 \%$ of the population lived in more than $10 \mathrm{~km}$ from the first level of care structure [6].

In terms of education level, $50.4 \%$ of household heads had a secondary or higher education and $9.2 \%$ had never been to school. Compared to the investigation 1- 2- 3, these results seem more less lower for illiterate (12.7\%) [16].

The vast majority of households surveyed were of Christian faith (79.1\%). According to the supposed cause of the disease, one in two respondents believed that it is the biomedical because that was the origin of the disease in the household and $16 \%$ thought a supernatural or metaphysical cause.

\subsection{Morbid States and Household Behavior}

The proportions of households experienced at least one case of disease during the last three months preceding the survey (94.8\%), seemed twice those found at Cilenge (45.9\%) [17]. These low levels of sick Cilenge which is a rural health zone over the city of Mbujimayi, be justified by the fact that the survey Cilenge came just months after the end of support in this part PS9FED province health, which would have made access to easy care and therefore improved health status of the population. The vast majority (84\%) cases of disease were linked to biomedical origin, that is to say that can be cured by modern medicine against $16 \%$ who were considered to be of supernatural cause (or metaphysical) where the situation envisaged happening to regain health, usually through the use of healers, magicians, herbalists The majority of people sick in the household was represented by those aged 0 - 5 years (40.7\%). This could be explained by the fact that children 0 to 5 years are more exposed to certain childhood diseases. The male patients were more affected with (58.3\%). This would be linked to the activities which engaged the man who sets out to develop certain illnesses and accidents explained by the fact that children 0 to 5 years are more exposed to certain childhood diseases. The male patients were more affected with (58.3\%). This would be linked to the activities which engaged the man who sets out to develop certain illnesses and accidents explained by the fact that children 0 to 5 years are more exposed to certain childhood diseases.

As for the behavior towards the disease, the households surveyed did not have the same behavior. A good part of respondents sick (8.1\%) said they had not used a modern health service. These results are slightly higher than Cilenge [17] and Cameroon [10], 17.1\% of patients had used traditional care. These results are lower than those found in Kinshasa (21\%) [18]. Private health structures were the main resort. This behavior confirms the thesis that the health system of DRC remained during the recession observed thanks to the efforts by churches and private. Our results confirm some studies [16] [19] that the variety of therapeutic itineraries observed in most countries in Africa, Then they face related diseases urbanization in Africa, few people seem to go to public health centers. Different hypotheses may explain this trend as a lack of access to modern health facilities (distance, cost) or a particular perception of these diseases that would 
bring the sick to other remedies (self-medication, traditional healers).

The organizational and functional factors of health facilities have a significant influence on the decisions and choices about therapeutic routes. The attitude of health staff perceived as unfriendly and unwelcoming visibly vis-à-vis patients, high absenteeism or delays at work, poor clinical diagnoses, lack of attention to the complainants, unequal access to resources available in the health centers, etc. are considered as obstacles that limit the use of nursing facilities. For these reasons a sick person living near a health facility rather go get check into another located in a very remote distance requiring cost and travel time, simply because it is guaranteed to find a proper management and quality care service [3] [17]. In our study, several reasons have advocated the choice of a health facility.

As they face the disease, few people seemed to see in public facilities (29\%). Different reasons can explain this trend as a lack of access to modern health facilities (distance, cost) or a particular perception of pathology that would bring the sick to other remedies (self-medication, traditional healers ...). These reasons care structure choices have been mentioned in other African studies [17]. In this study, it is the financial reason which is the first barrier (80.7\%).

\subsection{Results of the Bi-Variegated Analysis}

Regarding the factors associated with these various therapeutic routes, the results obtained in this study indicate that the use of modern care is related to the sex of the household head. Patients belonging to households headed by men had more luck access to modern care as those belonging to households headed by women $(\mathrm{P}<0.05)$. By cons, members of households headed by women used more traditional medicine $(\mathrm{P}<0.05)$.

However, members of households headed by women were more likely to abandon treatment $(\mathrm{P}<0.05)$. The results of empirical work COMMERYAS C. and Jean Rolin NDO [10] had also found the gender of household head had an influence on the demand for care. By cons, seeking care had no significant relationship with the gender of the household head to Kadutu (southern South Ki$\mathrm{vu} / \mathrm{DRC})[20]$.

The age of the household head does not affect the use of modern treatments $(P>0.05)$. These results corroborate those of Mushagalusa SP, [20] who had not also found a significant relationship between the age of the household head and recoures care in his study Kadutu (South Kivu).

However, age of household head significantly influences seeking care for illness in the household. It is observed that people belonging to households whose head is under 30 have given more to health care $(\mathrm{P}<0.05)$.

The individual's gender is a typical variable used in studies that seek to explain the inequalities of access to health care. In our study a significant association was found between access to care and sex of the individual. Women are more advanced to modern care than men $(\mathrm{P}<0.05)$. Conversely, men are more used to traditional care than women. Men were more applicable self-medication than 
women, also for non-consultation. If in our series our results corroborate those of Slim Haddad and Adrien Nougtara Valery Ridde [8] in Burkina Faso on the link between sex and access to care, they are different from the past that have shown that men have access more than women medical care.

Most studies analyzing the effect of age on access to care, confirm a relationship between the age of the individual and access to care [5] [9]. In this study, we observe that it is the children from 0 to 5 years for which the use of modern care is more important $(\mathrm{P}<0.05)$. And access to modern care decreases with age of the individual. Our results support [21], which demonstrated that the age of the individual acts negatively on access to care. All things being equal, the more the age of the individual increases more he gives to care. In other words, we give more access to care for children compared to adults. However, G. PIASER and Denis Raynaud [22], led to results opposite to modern medical consultation in France. They found that the age of the individual acts positively on the use of modern medical care. In other words, most people are older, the more they suffer from diseases whose treatment would require the services of modern medicine that have more powerful equipment.

While, whatever the age of the individual, the use of traditional care, self-medication and the renunciation of care remained the same.

The activity in which the head of household does not influence access to care $(P>0.05)$. However, the fact of belonging to a household headed by a leader who is part, have more recourse to medical specialists compared to the peasant, worker and employee.

When the householder has the level of education highest practically important part of sick people made use of health care. In this study, we observed that the level of education influences the householder access to modern treatments $(\mathrm{P}<$ 0.05). Although these results are contrary to some studies [20] which found no significant link between access to care and the level of the household head, by several African authors against revealed a significant link between level of education and the use of health care [14] [23].

The results of this study show no significant difference between religion and access to care. These results are in contrast to Eurelian Franckel [15], according to which the Christian faith was associated with external use in the direction of traffic.

Studies show that economic considerations are found to have a significant weight in the type of treatment used to induce and inequities in access to care between different income households [24] [25], Although other studies attempt to demonstrate that the level of income does not necessarily determine the use of health services [10] [26]. For some patients, the financial constraints are an obstacle to access to modern care that the physical barrier, given the existence of an acceptable geographic accessibility. Therefore, the decision to use a first-line self-medication or traditional therapy is more related to cost or free care to a rational therapeutic choice. These types of remedies are expressed through their soft and flexible approach including the financial capacity of the patients and 
considered ways to minimize expenses for care and manage such "domestic" the health of family members [14] [27] [28]. Our results clearly show that households reporting a more than 150 US dollars monthly income are more likely to have used the services of a professional public or private care during their episode of illness $(\mathrm{P}<0.05)$. Conversely, the use of traditional medicine, self-medication or the renunciation of care was a fallback for the poor. All things being equal, the propensity to use the services of a professional in an episode of illness, is almost three times higher in families in the quintile of highest income than it is in those quintile of lowest income. Work Slim Haddad, Adrien Nougtara Valery ridda [8], Daniele DUCHESNE [29].

Unlike the theoretical framework, in our study the household size does not influence access to care. Attitudes to the disease are the same in every household, no significant association was observed regardless of household size. These results conform to the studies that have not found a significant link between access to care and household size [2] [20].

The use of health services may be related to the distance, and attendance is often the most important for neighborhoods with a health facility. Substantially, the distance to the structure of care influences the use of modern care. The people traveling less than $5 \mathrm{~km}$ to reach healthcare facilities are more likely to access modern treatments $(\mathrm{P}<0.05)$. However, it should be noted that the level of utilization of health centers also depends on the type of pathology. Our results are consistent with many studies that have shown that indeed the consumption of modern health care, decreases with distance [7] [30].

Sovery significantly, the supposed cause of the disease influence significantly the use of modern health care. Thus, most attributed to the biomedical causes disease, the more we made use of modern health care $(P<0.05)$. Conversely, diseases supernatural or metaphysical causes are more oriented to traditional medicine or exorcisions by prayer. The same have also been made in rural areas of Senegal by FAYE SL LALOU R. and A. ADJAMAGOBO, [31] which showed in a study on therapeutic practices in malaria cases in children under 5 , parents resorted mainly to modern medicine for fever. But when the child was the seizure, Malaria was once perceived as a supernatural cause and the child was unfortunately led to the traditional healer or to the marabout. This fact had already been stated by others indicating that in African societies, the cultural distance between the population of health services is sometimes more important than the physical distance [32].

The choice of action may also be highly dependent on the perception of a serious nature of the disease modifying therefore the attitude of people who do not react upon the occurrence of a morbid episode apparently banal. Often it is the worsening state of health leading to an appeal "specialized" (healer or clinic), the choice depends on the perception of the disease [3] [25]. Popular representations trivialize fevers that occur and explain that the disease runs in first domestic way through self-medication [31] [33]. The universe of the patient moves progressively towards the traditional healer or health facility staff when the use of tradi- 
tional remedies s' proves ineffective and the disease begins to enter a critical and delicate stage. Thus, the perception of disease severity character changes the attitude of the people. This then encourages them to go to a resort "special" rather than "domestic". These attitudes to the disease for understanding why households do not consider some cases of serious diseases such systemically to resort immediately to health services as they emerge. However, whether educated or not, patients have all tend to resort to a consultation when the state of their health is getting worse or for serious conditions immediately.

In this study, the care financing modality was an important factor influencing access to care. Access to modern care was higher for households where the heads are able to support themselves $(\mathrm{P}<0.05)$. By cons, those whose costs are borne by the employer, longer be used traditional care, or given to health care. These results are consistent with the view that the exclusion of large proportions care is linked to all the provisions and operation of a health system in which lack of social protection and the introduction of the principle of user pays are directly place the burden of health spending on families. The pricing of services is a source of exclusion and inequity and this has been repeatedly demonstrated.

\section{Conclusions}

The DRC has ratified and acceded to several international instruments guaranteeing the right to health. Despite these commitments, the population is enormous health problems including unequal access to health care.

In this descriptive cross-sectional study, we set as a basic objective of determining the social factors that are the basis of access to health care inequalities. To achieve this, we have described the sociodemographic characteristics of the households, identify behaviors of the population to the disease in the household and determine the knowledge of the population's right to health.

Above all, it was imperative to know the living conditions of households in the city of Mbujimayi. Why the third chapter began with a description of the characteristics as demographic, economic, and the behavior of people facing the disease.

The results of this study have shown that socio-demographic and economic characteristics identified do not predispose this population to a good use of health services and in the current conditions it would be difficult, if not impossible to make fair the use of health services in the city of Mbujimayi.

The results of this research deliver more information on the one hand the problem of not seeking care, and secondly that the choice of the type of care.

The measure of inequality of access to health care through the three types of care (Care modern, traditional care, self-medication) shows that they are of different magnitude according to sex, age, occupation, education level, distance, and supposed state because of the disease, mode of care by households financing.

From the correlation analysis results, it was found that the following sociodemographic and economic factors: income, gender and age of head of house- 
hold, occupation CM, education, distance, gender and age of the individual. The etiological beliefs have emerged as significant for access to modern and traditional care for the renunciation of care.

\section{Conflicts of Interest}

The authors declare no conflicts of interest regarding the publication of this paper.

\section{References}

[1] Fournier, P. and Haddad, S. (1995) Factors Associated with the Use of Health Services in Developing Countries. Sociology Populations, Montreal, 289-325

[2] Morniche, P. (1995) Access to Care: Evolution of Inequality between 1980 and 1991. Economics and Statistics, 282, 3-19.

[3] Obrist, B., Iteba, N., Lengeler, C., et al. (2007) Access to Health Care in Contexts of Livelihood Insecurity: A Framework for Analysis and Action. PLoS Medicine, 4, e308. https://doi.org/10.1371/journal.pmed.0040308

[4] Mariko, M. (2003) Access to Quality Care: Results of an Empirical Study Conducted in Bamako (Mali), AUDIBERT and Went in Health Financing in African Countries and Low-Income Asia. Paris, Karthala, 41-58.

[5] Mariko, M. (2003) Quality of Care and the Demand for Health Services in Bamako, Mali: The Specific Roles of Structural, Process and Outcome Components. Social Science \& Medicine, 56, 1183-1196. https://doi.org/10.1016/S0277-9536(02)00117-X

[6] MiniPlan (DRC) PRSP (2007) Poverty, Insecurity and Exclusion in Kasai Oriental Province. 14.

[7] Gobbers, D. (2002) Equity in Access to Health Care in West Africa. ADSP, No. 38, 72.

[8] Haddad, S., Nougtara, A. and Ridde, V. (2004) Inequalities in Access to Health Services and Their Determinants in BURKINA FASO. Health, Company and Solidarity, No. 2, 203.

[9] Beresniak, A. and Gerard, D. (2008) Health Economics. Masson, Paris.

[10] Commeryas, C., et al. (2006) Seeking Behavior Study to Care and Drugs in Cameroon. Cahiers Health, 16

[11] Raynaud, D. (2005) Individual Determinants of Health Spending: The Influence of Social Class and Supplementary Health Insurance in Studies and Results. No. 378, DREES.

[12] Zougba, A.D. (2000) Services of Care and Quality in Burkina Faso: An Interpretation and Management of the Health Issue Particularly Advanced, Difficulties and Deficiencies, Ouagadougou, Burkina Faso. 22.

[13] MoH/DRC (2006) General Secretariat Building Strategy Health System (SSRS). http://www.minisanterd.cd/

[14] Coulibally, I. and Balla Keita Kuepe, M. (2008) The Determinants of Therapeutic Use in Mali between Sociocultural, Economic Factors and Geographical Accessibility. http://retro.erudit.org/livre/AIDELF/2008

[15] Franckal, A. (2004) The Seeking Behaviors Rural Health Care in Senegal: The Case of Febrile Children in Niakhar. Paris X University, Paris.

[16] Wembonyama, S., Mpaka, S. and Tshilolo, L. (2007) Medicine and Health in the 
Democratic Republic of Congo's independence in 3rd Republic. Medicine Tropical, 67, 447-457.

[17] Mitangala, P. (2009) Survey on Household Income of the Beneficiaries of PS9FED and Their Use of the Health System in Kasai Oriental. ESP/ULB.

[18] Manzambi, J.K. (2002) Determinants of Seeking Behavior Health Center in Urban Africa: Results of a Survey of Households Conducted in Kinshasa-Congo. Development and Health, No. 160.

[19] Diakite, B.D., Diarra, T. and Traores (1993) Use of Care and Medical Consumption in the District of Bankoni. Healing If the Mali, Orstom, Khartala, Paris, 343.

[20] Mushagalusa, S.P. (2005) Study of Socio-Economic Determinants of Access to the Use of Health Services by Households in the Health Zone Kadutu/South Kivu. Master's Degree, UNIKIN.

[21] Sow, B. (1994) Survey of the Will and the Ability of Households to Pay for Health Care in Three Provinces of Burkina Faso, the USAID Mission in Burkina Faso and the Division of Sectoral Reforms and Policies. Office of Health and Nutrition, Bureau for Global Programs Field Support and Research, US Agency for International Development.

[22] Plaser, G. and Raynaud, D. (2002) Medical Examination, the Influence of Income and Supplementary Insurance. Economic Review, 53, 113-133.

[23] Moussa, D., Yves de Hersan, A.M. and Anta Ta Dial, J. (2014) Demand Determinants of Peri-Urban Care in a Context of Subsidy in Pikine, Senegal. Studies and Documents, No. 15, CERDI. http://www.cerdi.org/ed

[24] Cissé, B., Luchini, S. and Moatti, J.P. (2004) The Effects of Cost Recovery Policies on the Demand for Care in Developing Countries: Conflicting Results of the Reasons. French Journal of Economics, 18, 111-149.

[25] Gessler, M.C., Msuya, D., Nkunya, M.H., Schar, A., Heinrich, M. and Tanner, M. (1995) Traditional Healers in Tanzania: The Perception of Malaria and Its Causes. Journal of Ethnopharmacology, 48, 119-130. https://doi.org/10.1016/0378-8741(95)01294-N

[26] Sy, I., Keita, M., Mostapha, O.T., Baddidy, L.O., Tanner, M. and Cisse, G. (2010) Use of Care and Use of Health Services in Nouakchott (Mauritania): Spatial Inequalities or Social Constraints? Health, 1, 13-21.

[27] Boidin, B. (1995) Health Equity in Sub-Saharan Africa: An Approach by the Health Threshold. Cahiers du GRATICE, 15, 169-211.

[28] Doumbouya, M.L. (2008) Accessibility of Health Services in West Africa: The Case of Guinea. Working Paper, University of Lyon II, Lyon.

[29] Duchenne, D. (1998) Duchenne Devaluation of the Function of the Health Care Demand in Tanzania Center for Research and Development in Economics (CRC). University of Montreal, Montreal.

[30] Lucas-Gabrielli, V., et al. (2001) Close to Care: A French Exception. CREDES, Paris, $92 \mathrm{p}$.

[31] Sylvain Landry, F. and Lalou Adjamagbo, R.A. (2004) Caring for Children Exclusively at Home for Malaria in Rural Senegal: An Effect of Poverty? African Population. Studies, 19, 221-240.

[32] Sakho, Y.L. (1997) Backstopping on Cost Recovery in the Health Region of Kaya. Ouagadougou, Ministry of Health, SCOAP.

[33] Baxerres, C. and Le Hesran, J.Y. (2004) Care Seeking for Fever in Children Sereer Country Senegal: Economic Constraint and Illness Perception. Social Science \& Health, 22, 19. https://doi.org/10.3406/sosan.2004.1634 